\title{
Therapeutic Management of Ivermectin Toxicity in a Calf: A Case Report
}

\author{
Pankaj Kumar Patel ${ }^{1}$, Sawita Kumari Patel ${ }^{2}$, Sonam Bhatt ${ }^{1}$, Desh Deepak ${ }^{1}$, \\ Arun Prabhakar ${ }^{3}$, Brijesh Patel $^{3}$, Chandrama Rabha ${ }^{1}$ and S.K. Dixit ${ }^{*}$ \\ ${ }^{1}$ Division of medicine, ICAR-Indian Veterinary Research Institute, Izatnagar-243122, India \\ ${ }^{2}$ Division of Veterinary Public Health, ICAR-Indian Veterinary Research Institute, \\ Izatnagar-243122, India \\ ${ }^{3}$ Division of Livestock Production and Management, ICAR-Indian Veterinary Research \\ Institute, Izatnagar-243122, India \\ *Corresponding author
}

\begin{abstract}
A B S T R A C T
A one-month-old, $30 \mathrm{~kg}$ calf was presented to Referral Veterinary Polyclinic ICAR-IVRI, Bareilly, with the history of anorexia, salivation, dullness, ataxia, laboured breathing and

Keywords

Ivermectin toxicity,

Salivation, Ataxia,

Labored breathing

Article Info

Accepted:

16 March 2018

Available Online:

10 April 2018 administration of bolus having a combination of fenbendazole $(3000 \mathrm{mg}$ ) and ivermectin (100mg). Clinical examination revealed pale mucous membrane, mydriasis, the absence of pupillary and menace reflex, sticky salivation, normal body temperature, tachycardia, tachypnoea, dull, depressed, sudden fall with tremors, abnormal posture and gait. Based on the history of overdosing of ivermectin drug and clinical signs presented by the animal the case was diagnosed as ivermectin toxicity. Due to the unavailability of specific antidote (picrotoxin, physostigmine) the case was managed by administration of Activated Charcoal@2g/kg BW PO TID, Diazepam@0.5 mg/kg bid up to the disappearance of clinical signs. Aggressive fluid therapy was given to the animal for three days. Supportive treatment included inj theophylline @ 6.6mg/kg BW IM, inj Vitamin B- complex with liver extract (3ml IM), inj chlorpheniramine maleate(Avil)@ $0.5 \mathrm{mg} / \mathrm{kg} \mathrm{BW} \mathrm{IM} \mathrm{daily} \mathrm{for}$ five days. The slight improvement was seen in calf after three days and complete recovery after the fifth day of the treatment.
\end{abstract}

\section{Introduction}

Ivermectin is a macrocyclic lactone comes under avermectin group is a fermentation product of Actinomycete, Streptomyces avermitilis, it is a mixture comprising $80 \%$ 22,23-dihydroavermectin B1a and 20\% 22,23dihydroavermectin B1b. It is very potent nematocide and endectocide but is not having activity against tapeworm and flukes (Prasad et al., 2006). It has a wide action against flies and larvae of parasitic dipteran flies (Campbell et al., 1984; McKellar et al., 1996). In mammals, macrocyclic lactones bind with gamma- aminobutyric acid type A - gated chloride channels of GABA A receptors (Sieghart et al., 2006). MLs binds with GABA A receptors in different sites than benzodiazepines, barbiturates, picrotoxins in the GABA receptor (Sieghart et al., 1995). In 
overdoses, enough MLs permeates the bloodbrain barrier that binds to GABA A receptors, as well as to glycine and voltage-gated chloride channels (Bloomquist et al., 2003; Trailovic et al., 2011). The preceding opening of chloride channels leads to chloride influx causes hyperpolarization and decreased firing of excitatory neurons develop clinical sign. Lower concentrations of avermectins cause excitatory signs (tremor, convulsion) due to reducing GABA effects. Gradually increase the concentration of avermectins leads to enhance GABA effect that leads to a progressive ataxia and CNS depression (Bloomquist et al., 2003). So avermectins may have CNS stimulatory effect at lower concentration and inhibitory effect (ataxia, depression) at higher concentration (Merola $e t$ al., 2012).

\section{Case Report and Result}

A one-month-old non-descript calf weighing $30 \mathrm{~kg}$ was admitted to Referral Veterinary Polyclinic of IVRI, Izatnagar with the history of anorexia, salivation, dullness and ataxia. Managemental history from owner showed administration of bolus having the combination of ivermectin (100mg/bolus) and fenbendazole $(3000 \mathrm{mg} /$ bolus) when the calf was showing signs of inappetence, soil licking, reduced water intake and abdominal pain. Clinical examination showed pale and cyanotic mucous membrane, mydriasis, severe weakness, dull and depressed, hypermetria and ataxia while walking and preferred recumbency with abnormal posture for a long time. Examination of the head revealed sticky salivation, slight nasal discharge, the absence of pupillary light reflex and menace reflex, normal body temperature $\left(100.7^{\circ} \mathrm{F}\right)$, tachycardia (115/min) and tachypnoea (30/min). Distant examination of calf showed shivering, tremors and incoordination of gait while walking and abnormal posture during recumbency and a few sticky faeces with mucus and yellowish coloured urine were observed in the calf.

\section{Haematological examination}

Haematology revealed leukocytosis (28 $\left.\mathrm{x} 10^{3} / \mathrm{cmm}\right)$, accompanied by slight neutrophilia and monocytosis, normal erythrogram (TEC- $9 \times 10^{6} / \mathrm{cmm}, \mathrm{Hb}-13$ $\mathrm{gm} / \mathrm{dl}$ ) and normal thrombocyte (420x $106 / \mathrm{cmm})$ count. On the basis of history and clinical signs, the case was diagnosed as Ivermectin toxicity because the margin of safety is much higher for fenbendazole than ivermectin for the calf. The calf was treated with Activated charcoal @ 2g/kg BW PO TID for one day, Diazepam @ $0.5 \mathrm{mg} / \mathrm{kg}$ twice in a day, IV up to the disappearance of signs. Aggressive fluid therapy Rintose @ 50ml/kg BW IV OD was given to the animal for three days. Supportive treatment included liver extract with vitamin B complex (B1+B2+B6+B12) @ 3ml IM, chlorpheniramine maleate@0.5 mg/kg BW IM and Theophylline @ $6.6 \mathrm{mg} / \mathrm{kg}$ BW IM BID for five days. Recovery from all clinical parameters was started after three days of treatment. Calf started taking milk from the third day of treatment with normal defecation and urination. Pupillary light reflex and menace reflex, mydriasis, salivation and nasal discharge were slightly cured after the 3rd day of successive treatment but slight ataxia was shown by the calf. Complete recovery was seen after the fifth day of treatment.

\section{Discussion}

Ivermectin is a GABA agonist which causes paralysis in susceptible arthropods and nematodes. It has been used for psoroptic mange, lice and Hypoderma larvae infestation in cattle. The activity of GABA finds only in the CNS and it does not readily cross the blood-brain barrier (Merck manual 11th edition). Avermectin induces paralysis via 
glutamate-gated Cl- channels which are only present in invertebrates (Arena et al., 1995; Cully et al., 1996). Avermectins have the affinity with GABA receptors in invertebrate receptors is about one hundredfold higher than the mammalian brain (Schaeffer and Haines, 1989). Ivermectin probably binds to glutamate-activated $\mathrm{Cl}$ - channels found in nematode nerve or muscle cells, which causes hyperpolarization by increasing permeability of chloride ions through the cell membrane; this results in paralysis of the parasite (Ikeda, 2003). The multidrug resistance gene (MDR 1) encoded to the P-glycoprotein pump which is present in intact Blood-Brain Barrier and protects from the neurotoxic effects of ivermectin (Wolstenholm et al., 2005; Schinkel et al., 1996). Ivermectin has minimum 10 fold Margin of safety than normal dose $0.2 \mathrm{mg} / \mathrm{kg}$ (Oral $/ \mathrm{SC}$ ) in adult cattle. Acute toxic signs are CNS depression, listlessness, ataxia, recumbency followed by death (Prasad et al., 2006). Calves can show toxic symptoms in only three times of the therapeutic doses of ivermectin, Toxic signs are ataxia, hypermetria and tremor and Colics. Generally, young animals are more sensitive to overdosing, react strongly and the prognosis is poorer than for adult animals (WHO Acute Hazard classification). Overdose of both fenbendazole and ivermectin amalgamation was reported in the calf but the margin of safety is higher for fenbendazole than ivermectin. The oral administrative dose of fenbendazole to cattle @ $7.5 \mathrm{gm} / \mathrm{kg}$ body weight was not causing any adverse effect (Prasad et al., 2006). Avermectins may have stimulatory CNS effects (tremors) at lower concentrations but inhibitory effects (ataxia, depression) at higher concentrations (Merola et al., 2012). Ivermectin toxicity produces signs in animals are mydriasis and depression followed by ataxia, recumbency and death (Canga et al., 2007; Prasad et al., 2006). Ivermectin toxicity is pursued GABA mediated cholinergic effects leading to symptoms like salivation, dyspnoea, diarrhoea and ataxia in calves (Basudde, 1989).

\section{Haematological examination}

\begin{tabular}{|l|c|c|}
\hline Haematological parameter & $\mathbf{0}$ day & $\begin{array}{c}\text { Reference range (Merck } \\
\text { veterinary manual } \mathbf{1 1}^{\text {th }} \text { edition) }\end{array}$ \\
\hline Hb (g/dl) & 13 & $8.0-15.0$ \\
\hline PCV $(\%)$ & 30 & $24-46$ \\
\hline TEC $(\mathbf{X 1 0} / \mathbf{c m m})$ & 9 & $5.0-10.0$ \\
\hline TLC $\left(\mathbf{1 0}^{\mathbf{3}} / \mathbf{c m m}\right)$ & 28 & $4.0-12.0$ \\
\hline Neutrophils \% & $\mathbf{4 8}$ & $15-45$ \\
\hline Lymphocytes \% & 43 & $48-75$ \\
\hline Monocytes\% & $\mathbf{9}$ & $2-7$ \\
\hline Eosinophils\% & 0 & $2-15$ \\
\hline Basophil\% & 0 & $0-2$ \\
\hline Platlet count (milllion/cmm) & 420 & $100-800$ \\
\hline
\end{tabular}


Fig: On the day of clinical examination

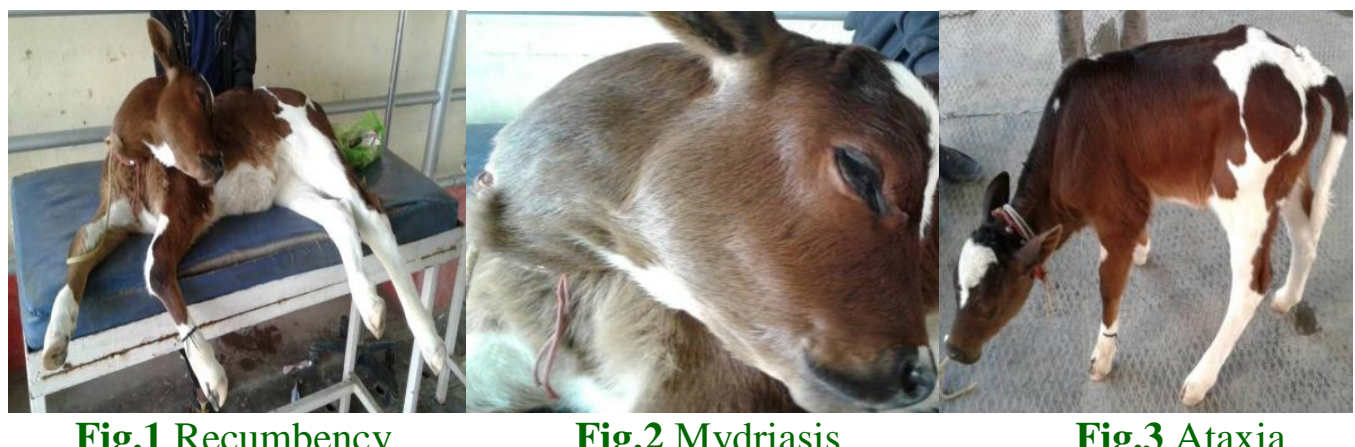

Fig.1 Recumbency

Fig.2 Mydriasis

Fig.3 Ataxia

The severity of toxicity depends on the route of administration and pharmacokinetic properties. Ivermectin is highly fat soluble, have a large volume of distribution, and gathering in fat tissue resulting in a long elimination half-life (Vercruysse et al., 2002; Chittrakarn et al., 2009). Subcutaneous administration of ivermectin delay's absorption than the oral route, but leads to an overall higher availability in plasma, a longer duration of action, and better efficacy (Molento et al., 2004). The ivermectin area under the plasma concentration-time curve (AUC) obtained after oral administration of the ivermectin at $0.2 \mathrm{mg} \mathrm{kg} /$ Body Weight (2476 $\mathrm{ng} \mathrm{d}^{-1} \mathrm{ml}^{-1}$ ) was higher than subcutaneous administration (459 $\mathrm{ng} \mathrm{d} \mathrm{ml}^{-1}$ ) (Lanusse et al., 1997). In cattle, plasma concentrations of $0.5-1 \mathrm{ng} / \mathrm{mL}$ are required for optimal anthelmintic activity against most gastrointestinal and lung nematodes (Lifschitz et al., 1999b); plasma concentrations of 0.5 $\mathrm{ng} / \mathrm{mL}$ also control Hypoderma spp. flies (Alvinerie et al., 1994). Also, intra-ruminal administration of ivermectin in cattle exposed that the bioavailability was $26 \%$ of that following subcutaneous administration (Chiu et al., 1990). Current studies show that ivermectin is not metabolised in the rumen (Andrews et al., 1996). In intestinal epithelium presence of P-glycoprotein responsible for comparatively less bioavailability by oral route administration (McKellar et al., 1996; Molento et al.,
2004).CYP3A4 finds in liver and intestine is the main isoform of the P450 enzyme responsible for ivermectin metabolism (Zeng et al., 1998). In liver and in the intestine CYP3A4 enzyme is responsible for the metabolism of many drugs (Lown et al., 1993; Thummel et al., 1996). A large fraction of administered ivermectin is excreted in the faeces and the concentration of ivermectin in dung over time is dependent on its route of administration (Herd, 1995). In cattle, 80 percent of the dose administered by subcutaneous injection is excreted in the dung during the first 35 days post-treatment (Sommer et al., 1992). Before administering new formulations of endectocide compounds results in special importance to the evaluation of pharmacokinetic behaviour and faecal excretion profiles of that drug. The investigation into the environmental impact, concerning pasture-land ecology is extremely important because the impact of faecal excreted ivermectin lead to potential effects on insect populations and dung degradation (Lumaret et al., 1993). In livestock administered ivermectin is partially excreted through the faeces and caused bad impact and hampers to development and fertility of coprophagous invertebrates (fly larvae, dung beetles, etc.) populations, which feed or breed on the dung of livestock. However, it prevents normal dung decomposition and recycling, has not been demonstrated (WHO Acute Hazard classification). 
Ivermectin toxicity is result of faulty managemental practices by dairy farmer. Due to lack of specific antidote such toxicities could be managed by supportive therapy and monitoring of patient till complete clinical recovery. Indiscriminate use of ivermectin leads to harmful effect on environmental health and life cycle of many useful organisms so judiciously use of the drug because it affects not only livestock health but also all living systems.

\section{References}

Alvinerie, M., Sutra, J. F., Galtier, P., and Toutain, P. L. (1994). Microdose d'ivermectine chez la vache laitiere: concentrations plasmatiques et residus dans le lait. Revue de Medecine Veterinaire, 145: 761-761.

Andrew, N. W., and Halley, B. A. (1996). Stability of ivermectin in rumen fluids. J. Vet. Pharmacol. Ther. 19(4): 295-299.

Arena, J. P., Liu, K. K., Paress, P. S., Frazier, E. G., Cully, D. F., Mrozik, H., and Schaeffer, J. M. (1995). The mechanism of action of avermectins in Caenorhabditis elegans: correlation between activation of glutamate-sensitive chloride current, membrane binding, and biological activity. J. Parasitol. 286-294.

Basudde, C.D.K., (1989). Clinical signs and biochemical changes in calves caused by injection of ivermectin. Vet. Q. 11(1): 2932.

Bloomquist, J. R. (2003). Chloride channels as tools for developing selective insecticides. Arch. Insect Biochem. Physiol. 54(4): 145-156.

Campbell, W. C., and Benz, G. W. (1984). Ivermectin: a review of efficacy and safety. J. Vet. Pharmacol. Ther. 7(1): 116.

Canga, A. G., Prieto, A. M. S., Liébana, M. J. D., Martínez, N. F., Vega, M. S., and Vieitez, J. J. G. (2009). The pharmacokinetics and metabolism of ivermectin in domestic animal species. Vet. J. 179(1): 25-37.

Chittrakarn, S., Janchawee, B., Ruangrut, P., Kansenalak, S., Chethanond, U., Kobasa, T., and Thammapalo, S. (2009). Pharmacokinetics of ivermectin in cats receiving a single subcutaneous dose. Res. Vet. Sci. 86(3): 503-507.

Chiu, S. H. L., Green, M. L., Baylis, F. P., Eline, D., Rosegay, A., Meriwether, H., and Jacob, T. A. (1990). Absorption, tissue distribution, and excretion of tritium-labeled ivermectin in cattle, sheep, and rat. J. Agric. Food Chem. 38(11): 2072-2078.

Cully, D. F., Wilkinson, H., Vassilatis, D. K., Etter, A., and Arena, J. P. (1996). Molecular biology and electrophysiology of glutamategated chloride channels of invertebrates. Parasitology, 113(S1): S191-S200.

Herd, R. (1995). Endectocidal drugs: ecological risks and counter-measures. Int. J. Parasitol. 25(8): 875-885.

Ikeda, T. (2003). Pharmacological effects of ivermectin, an antiparasitic agent for intestinal strongyloidiasis: its mode of action and clinical efficacy. Nihon yakurigaku zasshi. Folia pharmacologica Japonica, 122(6): 527-538.

Lanusse, C., Lifschitz, A., Virkel, G., Alvarez, L., Sanchez, S., Sutra, J. F. and Alvinerie, M. (1997). Comparative plasma disposition kinetics of ivermectin, moxidectin and doramectin in cattle. J. Vet. Pharmacol. Ther. 20(2): 91-99.

Lifschitz, A., Virkel, G., Pis, A., Imperiale, F., Sanchez, S., Alvarez, L. and Lanusse, C. (1999). Ivermectin disposition kinetics after subcutaneous and intramuscular administration of an oil-based formulation to cattle. Vet. Parasitol. 86(3): 203-215.

Lown, K. S., Ghosh, M., and Watkins, P. B. (1998). Sequences of intestinal and hepatic cytochrome P450 3A4 cDNAs are identical. Drug Metab. Dispos. 26(2): 185-187.

Lumaret, J. P., Galante, E., Lumbreras, C., Mena, J., Bertrand, M., Bernal, J. L. and 
Crowe, D. (1993). Field effects of ivermectin residues on dung beetles. J. Appl. Ecol. 428-436.

McKellar, Q.A. and Benchaoui, H.A. 1996. Avermectins and milbemycins. J. Vet.Pharmacol. Ther. 19: 331-351.

Merck veterinary manual $11^{\text {th }}$ edition

Merola, V.M. and Eubig, P.A. (2012). Toxicology of avermectins and milbemycins (macrocylic lactones) and the role of P-glycoprotein in dogs and cats. The Veterinary clinics of North America. J. Small Anim. Pract. 42(2): 313.

Molento, M.B., Lifschitz, A., Sallovitz, J., Lanusse, C., Prichard, R. (2004). Influence of verapamil on the pharmacokinetics of the antiparasitic drugs Ivermectin and moxidectin in sheep. J. Parasitol. Res. 92(2): 121-127.

Muser, R.K., Paul, J.W. (1984). Safety of fenbendazole use in cattle. Mod. Vet. Pract., 65(5): 371-374

Schaeffer, J. M., and Haines, H. W. (1989). Avermectin binding in Caenorhabditis elegans: a two-state model for the avermectin binding site. Biochem. Pharmacol., 38(14): 2329-2338.

Schinkel, A. H., Wagenaar, E., Mol, C. A., and van Deemter, L. (1996). P-glycoprotein in the blood-brain barrier of mice influences the brain penetration and pharmacological activity of many drugs. Journal of Clinical Investigation, 97(11): 2517.

Sieghart, W. (1995). Structure and pharmacology of gamma-aminobutyric acidA receptor subtypes. Pharmacol. rev. 47(2): 181-234.

Sieghart, W. (2006). Structure, pharmacology, and function of GABA A receptor subtypes. Adv. Pharmacol. Sci. 54: 231263.
Sommer, C., Steffansen, B., Nielsen, B. O., Grønvold, J., Jensen, K. M. V., Jespersen, J. B., and Nansen, P. (1992). Ivermectin excreted in cattle dung after subcutaneous injection or pour-on treatment: concentrations and impact on dung fauna. Bull. Entomol. Res. 82(2): 257264.

Thummel, K. E., O'shea, D., Paine, M. F., Shen, D. D., Kunze, K. L., Perkins, J. D., and Wilkinson, G. R. (1996). Oral first- pass elimination of midazolam involves both gastrointestinal and hepatic CYP3A- mediated metabolism. Clin. Pharmacol. Ther., 59(5): 491-502.

Trailovic, S. M., and Nedeljkovic, J. T. (2011). Central and peripheral neurotoxic effects of ivermectin in rats. J. Vet. Med. Sci. 73(5): 591-599.

Vani, Prasad. V., Koley, K.M. (2006). Treatment of Worm Infestation. In: Synopsis of Veterinary Pharmacology and Toxicology. (1st edn), Vahini Publications, India, 235-260.

Vercruysse, J., and Rew, R. S. (Eds.). (2002). Macrocyclic lactones in antiparasitic therapy. CABI.

WHO Acute Hazard classification.

Wolstenholme, A. J., and Rogers, A. T. (2005). Glutamate-gated chloride channels and the mode of action of the avermectin/milbemycin anthelmintics. Parasitol. 131(S1): S85S95.

Zeng, Z., Andrew, N. W., Arison, B. H., LufferAtlas, D., and Wang, R. W. (1998). Identification of cytochrome P4503A4 as the major enzyme responsible for the metabolism of ivermectin by human liver microsomes. Xenobiotica, 28(3): 313321.

\section{How to cite this article:}

Pankaj Kumar Patel, Sawita Kumari Patel, Sonam Bhatt, Desh Deepak, Arun Prabhakar, Brijesh Patel, Chandrama Rabha and Dixit, S.K. 2018. Therapeutic Management of Ivermectin Toxicity in a Calf: A Case Report. Int.J.Curr.Microbiol.App.Sci. 7(04): 1964-1969.

doi: https://doi.org/10.20546/ijcmas.2018.704.225 